\title{
ANÁLISE DO NÍVEL DE LEGENDA DE CLASSIFICAÇÃO DE AREAS URBANAS EMPREGANDO IMAGENS MULTIESPECTRAIS E HIPERESPECTRAIS COM OS MÉTODOS ÁRVORE DE DECISÃO C4.5 E FLORESTA RANDÔMICA
}

\section{Analysis of the Level of Detail in Classifications of Urban Areas with Optical VHR and Hyperspectral Images Using C4.5 Decison Tree and Random Forest Methods}

\author{
Camila Souza dos Anjos ${ }^{1,2}$ \\ Cláudia Maria de Almeida ${ }^{1}$ \\ Lênio Soares Galvão ${ }^{1}$ \\ Carlos Roberto Souza Filho ${ }^{3}$ \\ Marielcio Gonçalves Lacerda ${ }^{2}$ \\ Ronaldo Cristiano Prati 4 \\ 1 Divisão de Sensoriamento Remoto, Instituto Nacional de Pesquisas Espaciais - INPE. São José dos \\ Campos, Brasil. Email: camilasa@ieav.cta.br; almeida@dsr.inpe.br, lenio@dsr.inpe.br
}

${ }^{2}$ Subdivisão de Sensoriamento Remoto, Instituto de Estudos Avançados - IEAv, Força Aérea Brasileira FAB. São José dos Campos, Brasil. Email: marielcio@ieav.cta.br

3 Instituto de Geociências, Universidade de Campinas - UNICAMP. Campinas, Brasil. Email: beto@ige.unicamp.br

${ }^{4}$ Centro de Matemática Computação e Cognição, Universidade Federal do ABC. Santo André, Brasil. Email: rcprati@gmail.com

\section{Resumo:}

Ambientes urbanos representam uma das áreas mais desafiadoras do sensoriamento remoto devido à grande diversidade encontrada nos materiais presentes na sua superfície. O uso de imagens com alta resolução espacial e alta resolução espectral surge como uma alternativa para aplicações urbanas, pois a combinação destas duas características permite uma melhor detecção e discriminação de alvos. O presente trabalho tem um duplo objetivo: i) avaliar dois conjuntos de dados na classificação fina de alvos urbanos para dois níveis de legenda (com 11 e 38 classes de cobertura do solo): um deles composto exclusivamente por uma imagem orbital multiespectral (WV-2) e o outro conjunto composto exclusivamente por uma imagem aerotransportada hiperespectral (SpecTIR), ii) bem como testar o desempenho de dois métodos diferentes de classificação de imagens, Árvore de Decisão C4.5 e Floresta Randômica (Random Forest), para ambos os níveis de legenda. Oito experimentos de classificação foram realizados para atender a tais objetivos de investigar a eficácia dos sensores e dos métodos em dois níveis de detalhamento. Foram obtidas classificações de elevada acurácia. Demonstrou-se para todos os níveis de 
detalhamento e métodos que as classificações obtidas com dados do sensor SpecTIR apresentaram resultados significantemente superiores aos das classificações com dados do sensor WV-2. Palavras-chave: WorldView-2, ProSpecTIR V-S, Classificação de Cobertura do Solo Urbano, Métodos Não Paramétricos.

\begin{abstract}
:
Urban environments represent one of the most challenging areas for remote sensing analyses due to the great diversity of land cover materials found in their surface. The fusion of high spatial and high spectral resolution images arise as an alternative for urban applications, for the combination of these two characteristics allows better detection and discrimination of urban targets. The present work has a twofold objective: i) evaluate two datasets for the fine classification of urban targets at two levels of legend (with 11 and 38 land cover classes): one of them exclusively consisting of an orbital multispectral image (WV-2) and another one exclusively comprising an airborne hyperspectral image (SpecTIR), ii) as well as assess the performance of two different image classification methods, C4.5 Decision Tree and Random Forest, for both levels of legend. Eight classification experiments were executed to meet such objectives of investigating the efficacy of sensors and classification methods for the concerned two levels of detailing. The obtained classifications attained high accuracy. For all adopted levels of legend and methods, it was demonstrated that the classifications using SpecTIR data presented results significantly superior to those obtained with the WV-2 data.
\end{abstract}

Keywords: WorldView-2, ProSpecTIR V-S, Urban Land Cover Classification, Non-parametric Methods.

\title{
1. Introdução
}

Os materiais presentes no ambiente urbano apresentam alta diversidade espacial e espectral, pois incluem uma ampla gama de telhados, vias, calçadas, submetidos a intemperismo e de diversas idades, qualidades e composições químicas, entre outros aspectos. De acordo com Herold et al. (2003), os ambientes urbanos representam uma das mais desafiadoras áreas de análise para o sensoriamento remoto, pois sua diversidade espectral excede àquela encontrada nos ambientes naturais.

De acordo com Jensen (2009), quando se extrai informação urbana a partir de sensores remotos, geralmente é mais importante ter elevada resolução espacial do que resolução espectral. Já para Taherzadeh et al. (2012), no entanto, o sensoriamento remoto hiperespectral tem um papel essencial de aplicação para a análise de cenas urbanas complexas.

É impossível pensar na identificação de alvos urbanos com um sensor de baixa resolução espacial; entretanto, mesmo com o uso de imagens de alta resolução espacial, materiais com comportamentos espectrais semelhantes podem ser confundidos, uma vez que os sensores multiespectrais tradicionais possuem amplos canais espectrais que acomodam faixas relativamente extensas do espectro eletromagnético. Já um sensor hiperespectral de alta resolução espacial, cujas bandas são mais estreitas, poderá diferenciar os mesmos materiais e identificá-los corretamente. Deste modo, quanto mais estreitos forem os canais espectrais, isto é, quanto melhor for a resolução 
espectral do sensor, mais detalhes acerca do comportamento espectral dos alvos serão extraídos, o que possibilitará a diminuição considerável de erros de classificação.

Segundo Weber e O'Connell (2011), em certas aplicações, como, por exemplo, no mapeamento de áreas urbanas, a integração de alta resolução espacial e espectral é obrigatória para atingir um mapeamento suficientemente preciso com bons resultados na discriminação de alvos. Assim, o quadro ideal para a identificação de alvos urbanos seria a combinação dessas duas características, o que permitiria uma melhor detecção dos elementos que compõem o espaço urbano, sobretudo com o auxílio de classificadores automáticos de última geração.

Porém, sabe-se que os sensores hiperespectrais apresentam um deliberado trade-off, em que a resolução espacial é degradada em favor da melhora da resolução espectral (Manolakis et al., 2003). Os sensores orbitais hiperespectrais ainda não possuem alta resolução espacial, e portanto, tem crescido o uso de imagens hiperespectrais produzidas por sensores aerotransportados.

Os experimentos aqui relatados utilizam dois conjuntos de dados, sendo um deles formado por imagens de um sensor multiespectral orbital de alta resolução espacial (WorldView-2 ou simplesmente WV-2), e o outro formado por imagens de um sensor hiperespectral aerotransportado, igualmente de alta resolução espacial (ProSpecTIR V-S, doravante denominado somente como SpecTIR). Este artigo tem um duplo objetivo: i) avaliar dois conjuntos de dados na classificação fina de alvos urbanos para dois níveis de legenda (com 11 e 38 classes de cobertura do solo): um deles composto exclusivamente por uma imagem orbital multiespectral (WV-2) e o outro conjunto composto exclusivamente por uma imagem aerotransportada hiperespectral (SpecTIR), ii) bem como testar o desempenho de dois métodos diferentes de classificação de imagens: Árvore de Decisão C4.5 e Floresta Randômica (Random Forest) para ambos os níveis de legenda. Oito experimentos de classificação foram realizados para atender a tais objetivos de investigar a eficácia dos sensores e dos métodos em dois níveis de detalhamento.

É míster reconhecer que o uso de imagens de alta resolução espacial e espectral permite uma variedade de aplicações que requerem identificação fina dos materiais presentes no ambiente urbano. O presente trabalho pode ser aplicado na gestão urbana, reduzindo o tempo e custo de mapeamentos intraurbanos, assim como na identificação de materiais específicos de interesse relacionados à saúde pública, como, por exemplo, a identificação de telhas de cimento amianto, ou outros materiais de interesse civil e militar.

\section{Material e Métodos}

\section{1 Área de Estudo e Descrição das Imagens}

A área de estudo corresponde a um transecto localizado no Campus da Universidade Estadual de Campinas - UNICAMP, na cidade de Campinas - SP. Tal área foi escolhida devido à disponibilidade de dados e à diversidade de alvos urbanos contidos no local. Outra questão favorável à escolha da área de estudo foi a facilidade de acesso para as visitas de campo. Tais visitas foram realizadas em diferentes fases do trabalho e propiciaram a definição das classes e a aferição da acurácia das classificações.

O sensor orbital WorldView-2 (WV-2), da Digital Globe, possui uma banda pancromática e oito bandas multiespectrais, que apresentam, respectivamente, $0,46 \mathrm{~m}$ e 1,84 $\mathrm{m}$ de resolução espacial no nadir, sendo que, por questões de defesa, a banda pancromática foi reamostrada para $0,50 \mathrm{~m}$. 
As imagens são quantizadas em 11 bits. Além dos canais espectrais convencionais do azul (450510 $\mathrm{nm})$, verde $(510-580 \mathrm{~nm})$, vermelho $(630-690 \mathrm{~nm})$, e infravermelho próximo $(705-745 \mathrm{~nm})$, o sensor disponibiliza adicionalmente as bandas do azul costeiro $(400-450 \mathrm{~nm})$, amarelo (585-625 $\mathrm{nm})$, vermelho limítrofe (705-745 nm) e infravermelho próximo 2 (860-1040 nm) (Digital Globe, 2010). As imagens WorldView-2 utilizadas no presente trabalho foram adquiridas em 21 de junho de 2010 e 02 de julho de 2010. Com as duas cenas WV-2, elaborou-se o Modelo Digital de Superfície usado no procedimento de ortorretificação da cena de 02 de julho de 2010, em virtude de a mesma apresentar a menor angulação off-nadir, correspondente a $6,75^{\circ}$, além de $38,37^{\circ}$ de elevação solar e $0 \%$ de cobertura de nuvem.

O sensor hiperespectral aerotransportado ProSpecTIR V-S (SpecTIR) é um imageador que reúne 357 bandas espectrais na região espectral compreendida entre 0,4 e 2,5 $\mu \mathrm{m}$, com campo de visada instantânea (instantaneous field of view - IFOV) de 1,31 mr, resolução espacial intercambiável entre 1 e $5 \mathrm{~m}$, e uma resolução espectral de $5 \mathrm{~nm}$ (Wright et al., 2012). O imageamento utilizado para a atual pesquisa ocorreu em 17 de junho de 2010, com resolução espacial de $1 \mathrm{~m}$.

\subsection{Metodologia}

A sequência metodológica deste trabalho é apresentada na Figura 1. O primeiro passo do préprocessamento foi a conversão dos dois conjuntos de imagens para uma mesma grandeza física, o que permite a realização de análises e comparações entre os mesmos.

Os dados SpecTIR foram obtidos na grandeza física de radiância, ao passo que os dados WV-2 foram obtidos em valores de nível de cinza. Desta forma, inicialmente converteram-se as imagens WV-2 para radiância, utilizando a ferramenta "Radiância do WorldView" (WorldView Radiance) do ENVI 4.8, e em seguida, as imagens dos dois conjuntos de dados foram transformadas para reflectância de superfície por meio da ferramenta "Análise Rápida de Linha de Visão Atmosférica de Hipercubos Espectrais" (Fast Line-of-sight Atmospheric Analysis of Spectral Hypercubes FLAASH) do mesmo software. A ferramenta realiza a correção atmosférica das cenas e apresenta os dados resultantes na grandeza física de reflectância de superfície. Tal procedimento é necessário, tendo em vista que a atmosfera presente entre a superfície da Terra e o sensor é composta por diferentes gases e partículas em suspensão, que afetam a qualidade da imagem. De acordo com Andrade (2011), os efeitos de absorção por diferentes constituintes da atmosfera solicitam especial atenção quando do uso de sensores hiperespectrais, visto que adquirem dados em bandas estreitas e contíguas.

Após a correção atmosférica, as imagens WV-2 foram fusionadas utilizando o método GramSchmidt, disponível no ENVI 4.8, o qual simula a banda pancromática a partir das bandas multiespectrais. Uma transformação Gram-Schmidt é então aplicada à banda pancromática simulada e às bandas multiespectrais, em que a pancromática simulada é empregada como a primeira banda do conjunto resultante. Em seguida, essa primeira banda Gram-Schmidt é substituída pela banda pancromática de alta resolução, e uma transformação inversa é aplicada para formar a imagem sintética de saída (Laben e Brower, 2000). Tal método foi escolhido por não impor limite ao número de bandas de entrada e também por apresentar alto grau de similaridade espectral entre as bandas multiespectrais originais e as transformadas.

Posteriormente a fusão das bandas WV-2, as 8 bandas resultantes possuem $0,5 \mathrm{~m}$ de resolução espacial. Os dados SpecTIR não necessitaram ser fusionados, visto que todas as 357 bandas possuem a mesma resolução espacial $(1 \mathrm{~m})$. Desta forma, foi necessário reamostrar as bandas SpecTIR para a mesma resolução espacial das imagens fusionadas WV-2. Tal procedimento foi 
realizado com a ferramenta "Reprojetar" (Reproject) do ERDAS IMAGINE 9.0, utilizando o método de reamostragem pelo vizinho mais próximo. A partir de então, todos os dados utilizados no presente trabalho possuem a resolução espacial de $0,5 \mathrm{~m}$.

Para a ortorretificação das duas cenas, foi utilizada a ferramenta de "Dispositivo de Ortorretificação" (OrthoEngine) do PCI Geomatics. Para tal finalidade, foram utilizadas duas cenas WV-2 (21/06/2010 e 02/07/2010) com sobreposição espacial, por meio das quais foi gerado o Modelo Digital de Superfície (MDS).

As imagens utilizadas no presente trabalho foram registradas entre si (corregistradas) utilizando a ferramenta de "Sincronização Automática" (AutoSync) do ERDAS IMAGINE 9.0. Este procedimento teve o objetivo de gerar uma correspondência espacial entre as cenas, em vista da geometria diferenciada entre a cena aerotransportada e a orbital.

Após a ortorretificação, uma seleção de bandas SpecTIR foi realizada. Tal procedimento visa excluir as bandas visualmente compostas por ruídos. As imagens hiperespectrais possuem bandas contíguas, logo, não trabalham exclusivamente nas janelas atmosféricas como nos sensores multiespectrais. Sendo assim, há bandas nos intervalos do espectro eletromagnético chamadas de "bandas de absorção", que não permitem o imageamento e resultam em dados extremamente ruidosos. Ademais, para se reduzir o custo computacional e o uso de espaço em disco, foi criada uma "bad band list", ou lista de bandas ruins, composta por 86 bandas situadas em faixas de absorção, as quais foram excluídas dos procedimentos posteriores. Assim, a partir desse ponto, todo o processamento de dados SpecTIR baseou-se em 271 bandas.

O próximo passo foi a extração de atributos, realizada com o objetivo de extrair informações do conjunto de dados. Tais atributos são utilizados no processo de classificação, visto que os classificadores trabalham como mineradores de dados, identificando, em meio a um amplo conjunto de entrada, quais atributos são necessários para determinar a separação entre as classes.

O primeiro atributo gerado foi o Modelo Digital de Altura (MDA), que é obtido pela Equação 1. O MDS é o Modelo Digital de Superfície, anteriormente obtido, e MDT é o Modelo Digital de Terreno (MDT), gerado no software QGIS 2.8.3 por meio de uma interpolação entre pontos de controle obtidos em campo.

$$
\mathrm{MDA}=\mathrm{MDS}-\mathrm{MDT}
$$

Foram gerados no software ENVI 4.8, tanto para os dados WV-2 quanto para os dados SpecTIR, os atributos Componentes Principais (Principal Components Analysis - PCA), Fração de Ruído Mínima (Minimum Noise Fraction - MNF), Índice de Vegetação por Diferença Normalizada (Normalized Difference Vegetation Index - NDVI), Índice de Água por Diferença Normalizada (Normalized Difference Water Index - NDWI), Índice de Vegetação Ajustado pelo Solo (Soiladjusted Vegetation Index - SAVI), além de outras razões de bandas apresentadas por Leonardi (2010) para identificação de alvos urbanos. 


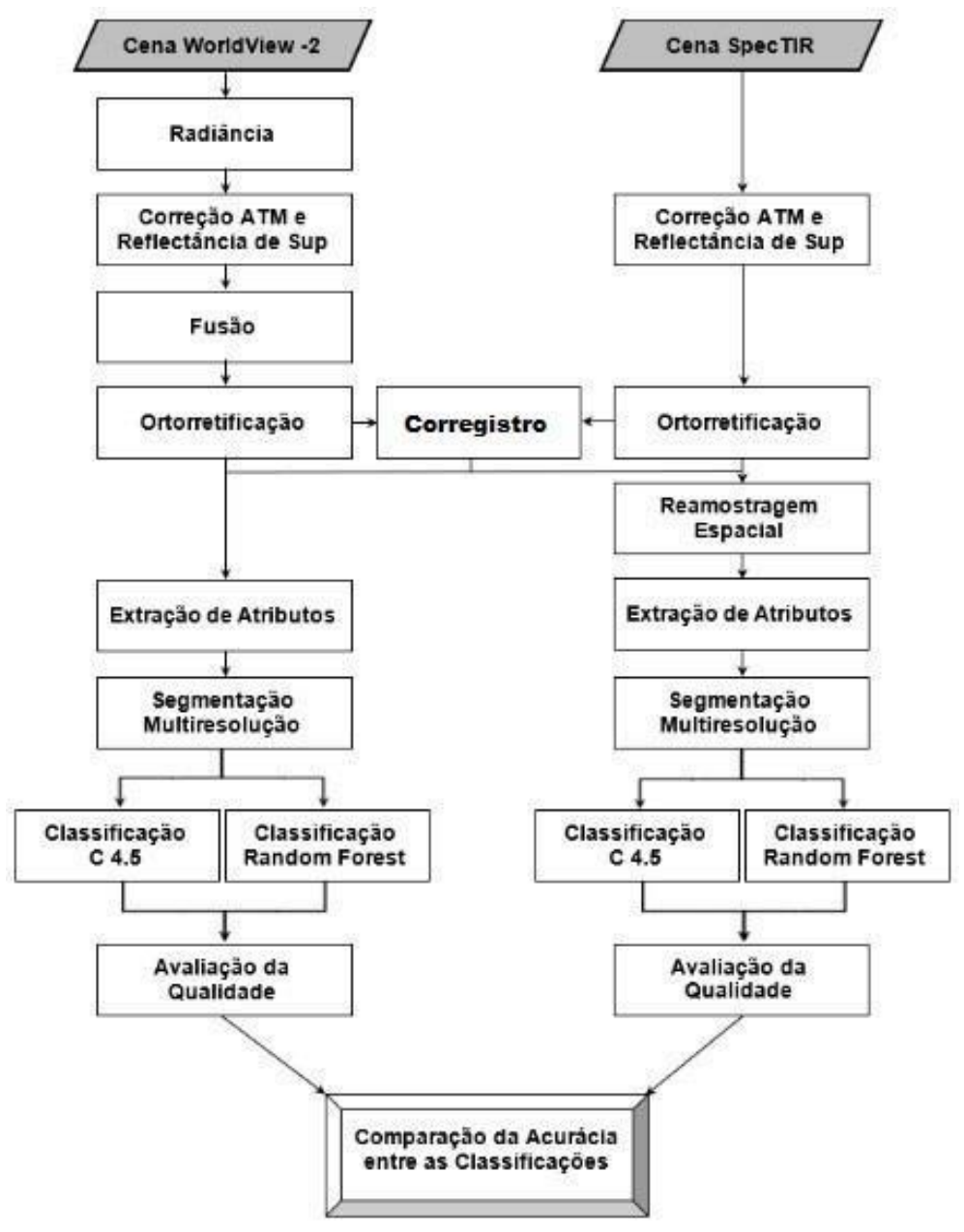

Figura 1: Procedimentos metodológicos realizados no presente trabalho.

O passo seguinte foi a realização da segmentação multirresolução no eCognition 8.7, visando particionar a imagem em segmentos, também chamados de objetos (Francisco e Almeida, 2012), sendo que objetos pequenos podem ser adequadamente analisados em uma resolução mais fina, ao passo que objetos maiores podem ser apropriadamente manipulados em uma resolução mais grosseira (Leonardi et al., 2013). Após a segmentação multirresolução, foi executado o ajuste por diferença espectral (spectral difference), também no eCognition 8.7. Este algoritmo é projetado para refinar os resultados da segmentação, por meio da similaridade espectral entre os segmentos vizinhos (Definiens, 2012).

A segmentação dos dados WV-2 foi realizada utilizando os seguintes parâmetros: Peso = 1 para todas as bandas, Escala $=30$, Forma $=0,8$, Compacidade $=0,9$ e Spectral Difference $=500$. Já a cena SpecTIR foi segmentada utilizando Peso $=1$ apenas para as bandas cujos centros coincidiam ou se aproximavam do centro das oito bandas multiespectrais do WV-2, e Peso $=0$ para as demais bandas, Escala $=50$, Forma $=0,8$, Compacidade $=0,9$ e Spectral Difference $=500$. Considerandose que foram utilizadas para a segmentação da imagem do SpecTIR as bandas cujo comprimento médio de onda equivalem ou mais se aproximam ao comprimento médio de onda das oito bandas multiespectrais do WV-2, e considerando-se também que as bandas do SpecTIR já haviam sido submetidas a reamostragem por vizinho mais próximo, a fim de que sua resolução espacial $(1,00$ $\mathrm{m})$ fosse coincidente com a resolução do WV-2 $(0,50 \mathrm{~m})$, torna-se impossível a plena compatibilidade de segmentação entre ambas as imagens, isto é, os segmentos ótimos produzidos para a segmentação da imagem SpecTIR não coincidem com aqueles produzidos para a segmentação da imagem WV-2. 
Após a segmentação, 20 segmentos amostrais foram coletados, também no eCognition 8.7, para todas as classes nos dois diferentes níveis de classificação abordados neste estudo. Não foi possível coletar um número maior de amostras para as classes devido à pequena extensão de algumas delas. As amostras coletadas para cada uma das classes em ambos os níveis de detalhamento foram exportadas no formato CSV (Comma Separated Values) e importadas pelo software livre WEKA (Waikato Environment for Knowledge Analysis) na versão 3.7, para serem utilizadas como dados de entrada para a extração de atributos e classificação dos dados. As classes são apresentadas no Quadro 1, em que o Nível 1 refere-se àquele de menor detalhamento, contendo 11 classes de cobertura, e o Nível 2 apresenta um alto grau de detalhamento da cena, apresentando 38 classes de cobertura do solo urbano, correspondentes à presença de materiais visualmente identificados em campo.

Após a coleta de amostras para todas as classes, foram aplicados os métodos de classificação Árvore de Decisão C4.5 e Random Forest no software WEKA. Há softwares gratuitos que realizam classificação utilizando o C4.5 com base em segmentação, a exemplo do InterIMAGE (LVC, 2016) e GeoDMA (Körting et al., 2013). No entanto, eles são comparativamente limitados quando comparados ao eCognition em relação à oferta de atributos, que é substancialmente menor em ambos. Além disso, esses dois softwares apresentam restrições quanto à robustez para lidar com grande número de bandas de entrada, que é o caso deste trabalho, o qual opera com centenas de bandas.

Segundo Han et al. (2012), os algoritmos de árvores de decisão foram originalmente planejados para classificação, no qual uma árvore de decisão é construída em uma estrutura de fluxograma (ou diagrama de fluxo). Uma árvore de decisão pode ser usada para classificar um caso (conjunto de dados) a partir da raiz da árvore e movendo-se por ela, até que uma folha seja detectada. Em cada nó de decisão (teste a ser realizado com um único atributo), o resultado do caso para o teste no nó é determinado, e a atenção se desloca para a raiz da subárvore correspondente a este resultado (Quinlan, 2014). Assim, o resultado do classificador é encontrado por meio de uma sequência de decisões, em que um conjunto de regras é implementado, começando do nó-raiz e finalizando no nó-terminal (folha), que representa a classe para a qual o objeto (segmento da imagem) foi classificado (Tso; Mather, 2009). As árvores geradas neste trabalho para o Nível 1, com 11 classes, possuem em média 140 nós, enquanto as árvores geradas para o Nível 2, com 38 classes, possuem em média 180 nós. Dada a dimensionalidade das árvores geradas, torna-se impossível a inclusão das mesmas neste artigo, maiores informações sobre o tema em: Han et al. (2012).

O método C4.5 gerou duas árvores de decisão para os dados WV-2 e mais duas para os dados SpecTIR. As quatro árvores do método C4.5 foram implementadas manualmente no eCognition 8.7, gerando quatro classificações.

O método Random Forest é uma técnica de classificação introduzida por Breiman (2001), que utiliza um conjunto de árvores de decisão e vetores aleatórios independentes. O conjunto de amostras de treinamento original é dividido em subconjuntos que geram árvores de decisão descorrelacionadas. Tal "floresta" de árvores gera uma classificação final, cuja saída é determinada pela maioria dos votos vencedores das árvores (Gislason et al., 2006). A técnica possui a capacidade de lidar com variáveis explicativas fracas e também com dados de entrada de elevadas dimensões, o que tornou o método atraente para a classificação de imagens hiperespectrais (Walton, 2008).

No presente artigo, o método gerou dez árvores de decisão para todas as quatro análises, dados WV-2 nos dois níveis de detalhamento e dados SpecTIR nos dois níveis de detalhamento. Assim, 40 árvores foram geradas no WEKA 3.7 e implementadas no eCognition 8.7, gerando 40 classificações. Foi necessário exportar todas as classificações no formato shapefile para que, utilizando a informação do nome da classe de cada segmento, um programa em Visual Basic 
pudesse ser implementado para realizar a contagem de votos (voting), e após a comparação entre as árvores, gerar um novo shapefile com o resultado final para cada conjunto de dados nos dois níveis de detalhamento. Por fim, produziram-se quatro classificações Random Forest em definitivo, tais classificações são apresentadas na Seção 3 (Resultados e Discussões).

Métricas de avaliação da qualidade das classificações foram aplicadas a cada uma das oito classificações finais. Para cada classificação, foi gerado um conjunto individual de pontos aleatórios. Com base nas considerações de Congalton e Green (2009), para as classificações do Nível 1, com 11 classes, o objetivo era ter 50 pontos aleatórios sobre a área de cada classe para então realizar a validação do resultado. Já para as classificações do Nível 2, com 38 classes, o objetivo era ter 75 pontos aleatórios sobre a área de cada classe. Entretanto, tal objetivo não foi alcançado em sua totalidade, haja vista o tamanho reduzido de algumas classes, que não seriam capazes de comportar esse grande número de pontos. Exemplos dessa limitação referem-se às classes Manta Asfáltica, Lona, Piscina de Vinil, Concreto Pintado de Vermelho, entre outras, que se resumem a poucos pixels na imagem.

Quadro 1: Níveis hierárquicos de detalhamento.

\begin{tabular}{|c|c|c|}
\hline & NIVEL 1 & NIVEL 2 \\
\hline \multirow{38}{*}{ CLASSES } & Solo Exposto & Solo Exposto \\
\hline & \multirow{2}{*}{ Piscina } & Piscina de Azulejo \\
\hline & & Piscina de Vinil \\
\hline & Lago & Lago \\
\hline & Sombra & Sombra \\
\hline & Vegetação Rasteira & Vegetação Rasteira \\
\hline & Vegetação Arbórea & Vegetação Arbórea \\
\hline & \multirow{2}{*}{ Pavimentação Não -Viária } & Pedra Mineira \\
\hline & & Carvão Coque \\
\hline & \multirow{4}{*}{ Pavimentação Viária } & Asfalto \\
\hline & & Asfalto Pintado de Vermelho \\
\hline & & Asfalto Pintado de Branco \\
\hline & & Bloquete \\
\hline & \multirow{7}{*}{$\begin{array}{l}\text { Materiais Mistos } \\
\text { (Pavimentação e } \\
\text { Cobertura) }\end{array}$} & Argamassa de Cimento \\
\hline & & $\begin{array}{c}\text { Argamassa de Cimento Pintada de } \\
\text { Vermelho }\end{array}$ \\
\hline & & $\begin{array}{l}\text { Argamassa de Cimento Pintada de } \\
\text { Verde }\end{array}$ \\
\hline & & Concreto Pintado de Amarelo \\
\hline & & Concreto Pintado de Vermelho \\
\hline & & Concreto \\
\hline & & Concreto Impermeabilizado \\
\hline & \multirow{10}{*}{ e Coberturas Diversas } & Vidro Aramado \\
\hline & & Fibra de Vidro \\
\hline & & Pastilha Esmaltada \\
\hline & & Fibrocimento CRFS \\
\hline & & Fibrocimento com Amianto \\
\hline & & Policarbonato \\
\hline & & Acrílico \\
\hline & & Plástico \\
\hline & & Lona \\
\hline & & Manta Asfáltica Aluminizada \\
\hline & \multirow{6}{*}{ Coberturas Metálicas } & Aço Galvanizado Brilhante \\
\hline & & Aço Galvanizado com Ferrugem \\
\hline & & Aço Galvanizado Fosco \\
\hline & & Galvalume Tipo A \\
\hline & & Galvalume Tipo B \\
\hline & & Galvalume Tipo C \\
\hline & \multirow{2}{*}{ Coberturas Cerâmicas } & Cerâmica Iluminada \\
\hline & & Cerâmica Escura \\
\hline
\end{tabular}

O cruzamento espacial da localização dos pontos aleatórios com o nome da classe correspondente no dado de referência (obtido com o auxílio de fotointérpretes especialistas, com base na informação adquirida em visitas de campo ao Campus da Unicamp), e nas classificações 
realizadas, foi realizado no software QGIS 2.8.3. Assim, para cada classificação foi criado um arquivo de pontos aleatórios, no formato shapefile, com uma coluna da tabela de atributos associada ao nome da classe daquele ponto na referência e outra coluna associada ao nome da classe daquele ponto na classificação. Por meio dos dados presentes nas tabelas de atributos, foram calculadas as matrizes de confusão, a exatidão global, o índice Kappa e os erros de acurácia do produtor e consumidor para cada classificação. Por fim, foi realizado o teste de hipótese Z (Congalton; Green, 2009), com nível de significância de 5\% (intervalo de confiança de 95\%), para verificar a significância estatística das diferenças de acurácia entre as classificações. As classificações foram confrontadas da seguinte maneira: para ambos os níveis de detalhamento, analisou-se a diferença de desempenho entre os conjuntos de dados WV-2 e SpecTIR e a diferença de desempenho entre os métodos C4.5 e Random Forest.

\section{Resultados e Discussão}

As quatro classificações resultantes para o nível de legenda 1 são apresentadas na Figura 2, e a Figura 3 apresenta a legenda para as 11 classes de cobertura do solo urbano para as classificações deste nível de detalhamento. As Tabelas 1 e 2 apresentam as avaliações de qualidade das classificações do Nível de Legenda 1. A Figura 4 apresenta as classificações para o Nível de Legenda 2, e na Figura 5, a legenda de classes para este nível de detalhamento. As Tabelas 3 e 4 apresentam as avaliações de qualidade das classificações do Nível de Legenda 2.

Tabela 1: Avaliação da qualidade da classificação dos dados WV-2 com o método C4.5 e com o método Random Forest, para o Nível de Legenda 1.

\begin{tabular}{|c|c|c|c|c|}
\hline & \multicolumn{2}{|c|}{ Método C4.5 } & \multicolumn{2}{|c|}{ Método Random Forest } \\
\hline Exatidão Global & \multicolumn{2}{|c|}{$85,57 \%$} & \multicolumn{2}{|c|}{$80,37 \%$} \\
\hline Kappa & \multicolumn{2}{|c|}{0,8333} & \multicolumn{2}{|c|}{0,7743} \\
\hline $\begin{array}{l}\text { Avaliação da Exatidão das } \\
\text { Classes }\end{array}$ & \begin{tabular}{|c|} 
Exatidão do \\
Produtor
\end{tabular} & $\begin{array}{l}\text { Exatidão do } \\
\text { Consumidor }\end{array}$ & $\begin{array}{l}\text { Exatidão do } \\
\text { Produtor }\end{array}$ & $\begin{array}{l}\text { Exatidão do } \\
\text { Consumidor }\end{array}$ \\
\hline Cerâmica & 1,0000 & 0,7353 & 1,0000 & 0,8485 \\
\hline Coberturas Metálicas & 0,7582 & 0,9583 & 0,8046 & 0,7368 \\
\hline $\begin{array}{c}\text { Materiais Mistos e } \\
\text { Coberturas Diversas }\end{array}$ & 0,8582 & 0,6250 & 0,7483 & 0,5000 \\
\hline Lago & 1,0000 & 0,9402 & 1,0000 & 0,9216 \\
\hline Pavimentação Não-Viária & 0,9556 & 0,9556 & 0,9412 & 0,9275 \\
\hline Pavimentação Viária & 0,8535 & 0,8024 & 0,7031 & 0,7759 \\
\hline Piscina & 0,9706 & 1,0000 & 1,0000 & 1,0000 \\
\hline Solo Exposto & 0,8378 & 0,9394 & 0,8571 & 0,8824 \\
\hline Sombra & 0,8279 & 0,9319 & 0,7782 & 0,9224 \\
\hline Vegetação Arbórea & 0,8669 & 0,9060 & 0,7800 & 0,8228 \\
\hline Vegetação Rasteira & 0,8021 & 0,8493 & 0,7739 & 0,8523 \\
\hline
\end{tabular}

Tabela 2: Avaliação da qualidade da classificação dos dados SpecTIR com o método C4.5 e o método Random Forest, para o Nível de Legenda 1. 


\begin{tabular}{|c|c|c|c|c|}
\hline & \multicolumn{2}{|c|}{ Método C4.5 } & \multicolumn{2}{|c|}{ Método Random Forest } \\
\hline Exatidão Global & \multicolumn{2}{|c|}{$87,26 \%$} & \multicolumn{2}{|c|}{$89,66 \%$} \\
\hline Kappa & \multicolumn{2}{|c|}{0,8524} & \multicolumn{2}{|c|}{0,8821} \\
\hline $\begin{array}{l}\text { Avaliação da Exatidão das } \\
\text { Classes }\end{array}$ & $\begin{array}{l}\text { Exatidão do } \\
\text { Produtor }\end{array}$ & $\begin{array}{l}\text { Exatidão do } \\
\text { Consumidor }\end{array}$ & $\begin{array}{l}\text { Exatidão do } \\
\text { Produtor }\end{array}$ & $\begin{array}{l}\text { Exatidão do } \\
\text { Consumidor }\end{array}$ \\
\hline Cerâmica & 1,0000 & 0,8947 & 0,9667 & 1,0000 \\
\hline Coberturas Metálicas & 0,8947 & 1,0000 & 0,9000 & 1,0000 \\
\hline $\begin{array}{c}\text { Materiais Mistos e } \\
\text { Coberturas Diversas }\end{array}$ & 0,9655 & 0,6614 & 0,9821 & 0,6011 \\
\hline Lago & 1,0000 & 1,0000 & 1,0000 & 1,0000 \\
\hline Pavimentação Não-Viária & 0,9643 & 1,0000 & 0,7941 & 1,0000 \\
\hline Pavimentaç̃o Viária & 0,8500 & 0,8395 & 0,8804 & 0,8438 \\
\hline Piscina & 1,0000 & 0,9667 & 0,9655 & 1,0000 \\
\hline Solo Exposto & 0,8261 & 0,8261 & 0,9268 & 0,9744 \\
\hline Sombra & 0,6748 & 0,9929 & 0,8785 & 0,9938 \\
\hline Vegetação Arbórea & 0,8973 & 0,7721 & 0,9397 & 0,9167 \\
\hline Vegetaç̃o Rasteira & 0,9242 & 0,9155 & 0,7439 & 0,9760 \\
\hline
\end{tabular}

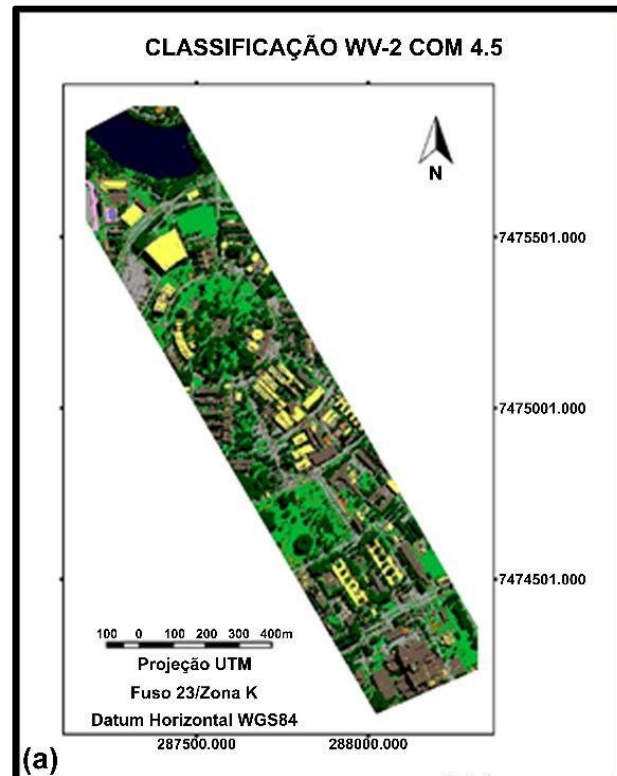

CLASSIFICAÇÃO SPECTIR COM 4.5

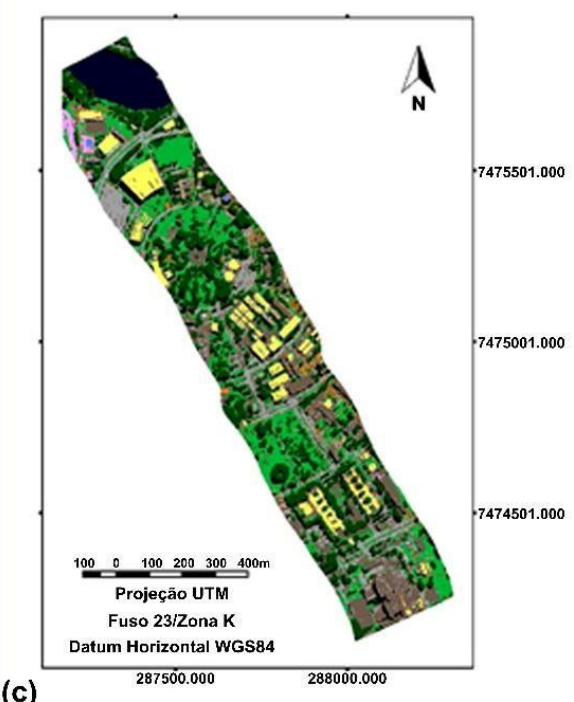

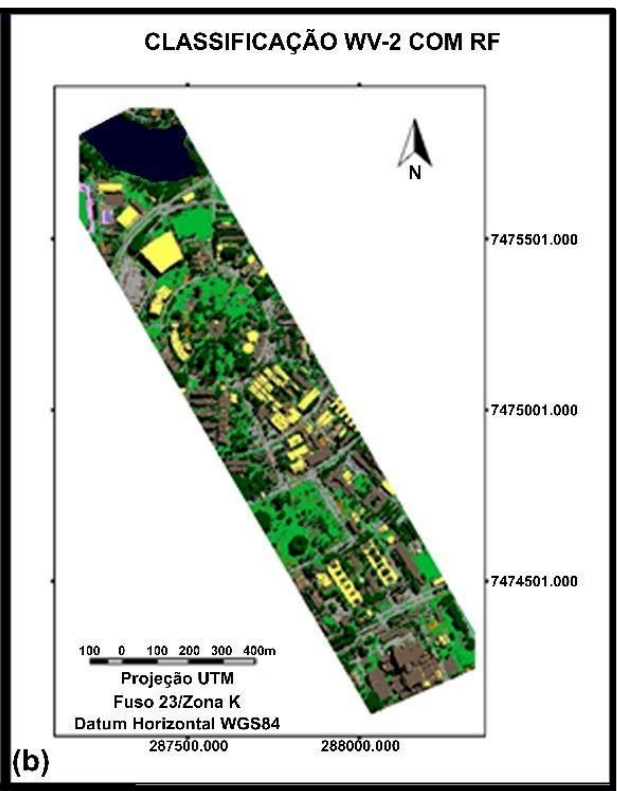

(b)

CLASSIFICAÇÃO SPECTIR COM RF

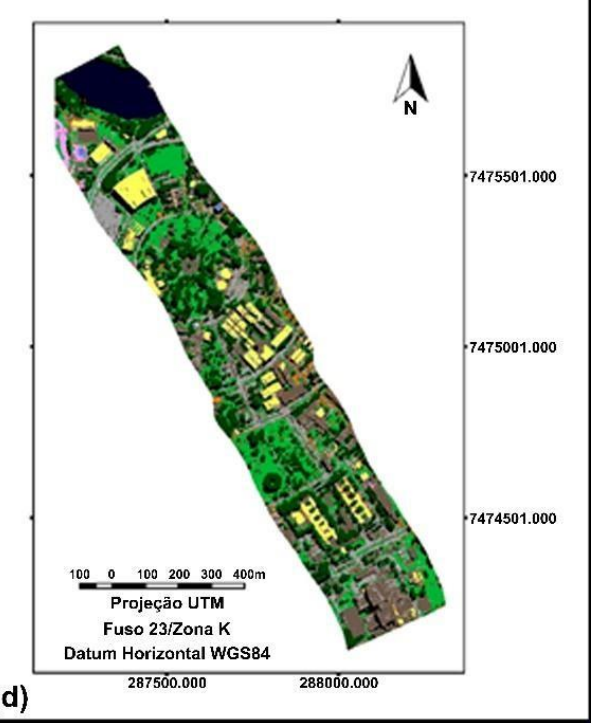

Figura 2: Classificações para o nível detalhamento 1. Imagem WV-2 com o método C4.5 (a), imagem WV-2 com o método Random Forest (b), imagem SpecTIR com o método C4.5 (c) e imagem SpecTIR com o método Random Forest (d). 


\begin{tabular}{|c|c|c|}
\hline \multicolumn{3}{|c|}{ Legenda } \\
\hline Cerâmica & Pavimentação Nao-Viária & I Sombra \\
\hline Materiais Mistos e Coberturas Diversas & Pavimentação Viária & Vegetação Arbórea \\
\hline Coberturas Metálicas & Pisana & Vegetaçäo Rasteira \\
\hline Lago & Solo Exposto & \\
\hline
\end{tabular}

Figura 3: Legenda para as classificações do Nível de Legenda 1.

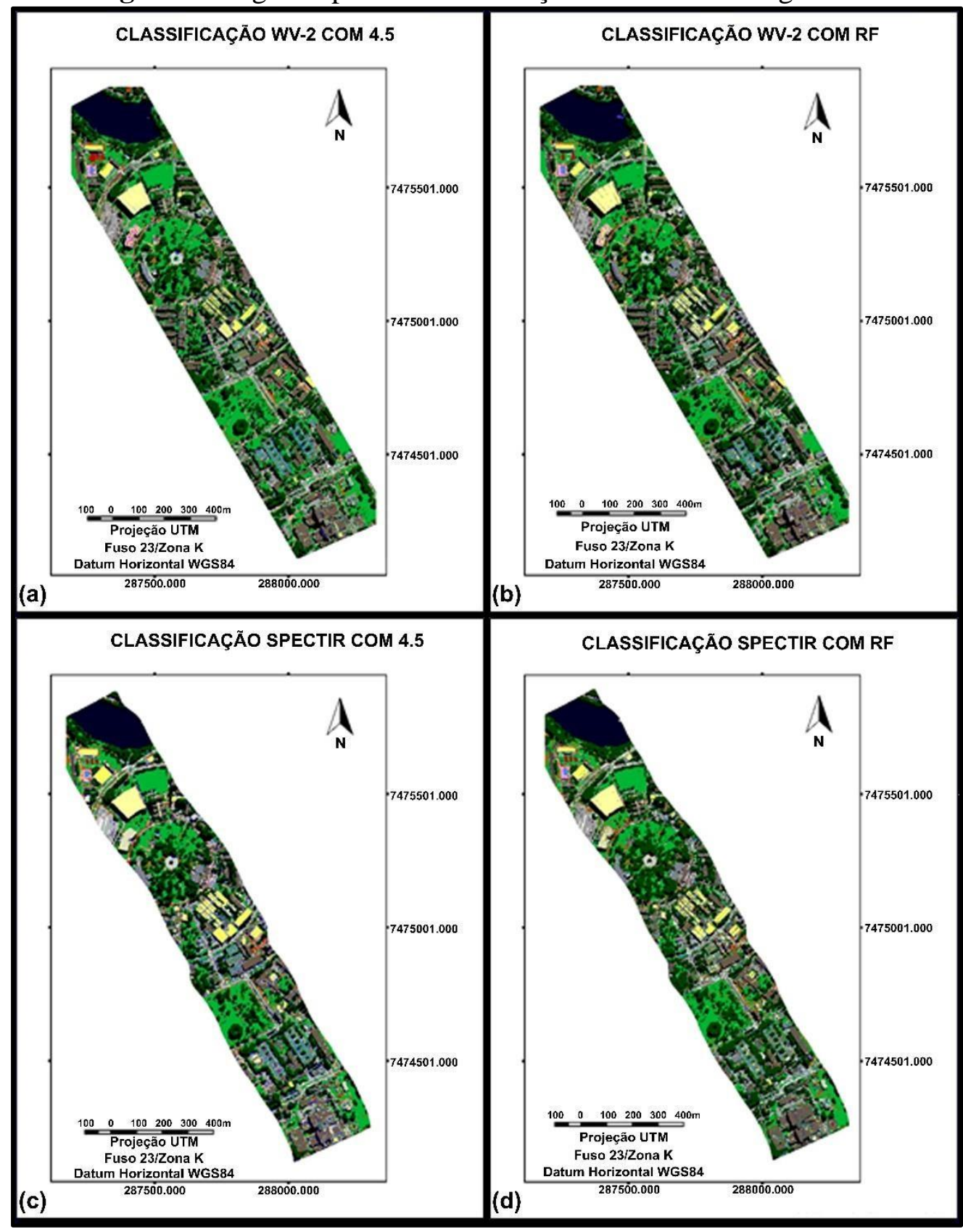

Figura 4: Classificações para o nível detalhamento 2. Imagem WV-2 com o método C4.5 (a), imagem WV-2 com o método Random Forest (b), imagem SpecTIR com o método C4.5 (c) e imagem SpecTIR com o método Random Forest (d). 


\begin{tabular}{|c|c|c|c|}
\hline \multicolumn{4}{|c|}{ Legenda } \\
\hline Acco Galvanizado Fosco & Carvão Coque & Fibrocimento CRFS & Piscina de Azulejo \\
\hline Aço Galvanizado Brilhante & Cerâmica Escura & Fibra de Vidro & Piscina de Vinil \\
\hline Aço Galvanizado Ferrugem & Cerâmica Iluminada & Galvalume A & Plástico \\
\hline Acrílico & Cimento & Galvalume B & Policarbonato \\
\hline Fibrocimento com Amianto & Cimento Pintado de Verde & Galvalume C & Solo Exposto \\
\hline Asfalto & Cimento Pintado de Vermelho & Lago & Sombra \\
\hline Asfalto Pintado Branco & Concreto & Lona & Vegetação Arbórea \\
\hline Asfalto Pintado Vermelho & Concreto Impermeabilizado & Manta Asfáltica Aluminizada & Vegetação Rasteira \\
\hline Bloquete & Concreto Pintado de Amarelo & Pastilha Esmaltada & Vidro Aramado \\
\hline & Concreto Pintado de Vermelho & Pedra Mineira & \\
\hline
\end{tabular}

Figura 5: Legenda para as classificações do Nível de Legenda 2.

Para cada um dos métodos, analisou-se a diferença de desempenho entre os conjuntos de dados. Essa mesma sequência de comparações gerou os testes de hipótese para o Nível de Legenda 2. Todos os testes rejeitaram as hipóteses de similaridade entre as classificações testadas. Assim, provou-se, para o Nível de Legenda 1, que o índice Kappa na classificação dos dados WV-2 com o método C4.5 é significantemente superior que para o método Random Forest.

Tabela 3: Avaliação da qualidade da classificação dos dados WV-2 com o método C4.5 e com o método Random Forest para o Nível de Legenda 2.

\begin{tabular}{|c|c|c|c|c|}
\hline & \multicolumn{2}{|c|}{ Método C4.5 } & \multicolumn{2}{|c|}{ Método Random Forest } \\
\hline Exatidão Global & \multicolumn{2}{|c|}{$80,17 \%$} & \multicolumn{2}{|c|}{$74,94 \%$} \\
\hline Kappa & \multicolumn{2}{|c|}{0,7807} & \multicolumn{2}{|c|}{0,7215} \\
\hline Avaliação da Exatidão das Classes & $\begin{array}{c}\text { Exatidão do } \\
\text { Produtor }\end{array}$ & $\begin{array}{l}\text { Exatidão do } \\
\text { Consumidor }\end{array}$ & $\begin{array}{l}\text { Exatidão do } \\
\text { Produtor }\end{array}$ & $\begin{array}{l}\text { Exatidão do } \\
\text { Consumidor }\end{array}$ \\
\hline Aço Galvanizado Brilhante & 0,5891 & 0,8172 & 0,6288 & 0,6803 \\
\hline Aço Galvanizado Ferrugem & 1,0000 & 0,8519 & 0,5429 & 0,4872 \\
\hline Aço Galvanizado Fosco & 0,8390 & 0,5470 & 0,7404 & 0,5274 \\
\hline Acrilico & 1,0000 & 0,2203 & 0,5000 & 0,0877 \\
\hline Amianto & 0,9167 & 0,8661 & 0,8450 & 0,7758 \\
\hline Asfalto & 0,6779 & 0,8770 & 0,6263 & 0,6179 \\
\hline Asfalto Pintado Branco & 0,5750 & 0,4894 & 0,3607 & 0,2857 \\
\hline Asfalto Pintado Vermelho & 0,1667 & 1,0000 & 0,5806 & 0,7200 \\
\hline Bloquete & 0,7636 & 0,3387 & 0,6667 & 0,2535 \\
\hline Carvão Coque & 0,9072 & 0,9072 & 0,8824 & 0,9146 \\
\hline Cerâmica Escura & 0,5349 & 0,1756 & 0,7500 & 0,3358 \\
\hline Cerâmica Iluminada & 0,5455 & 1,0000 & 0,9091 & 0,9091 \\
\hline Cimento & 0,5882 & 0,2273 & 0,5455 & 0,1875 \\
\hline Cimento Pintado de Verde & 0,7007 & 0,8803 & 0,5952 & 0,8333 \\
\hline Cimento Pintado de Vermelho & 0,7578 & 0,6424 & 0,5854 & 0,8889 \\
\hline Concreto & 0,6848 & 0,8185 & 0,7151 & 0,7859 \\
\hline Concreto Impermeabilizado & 0,7568 & 0,8400 & 0,7961 & 0,8723 \\
\hline Concreto Pintado de Amarelo & 0,7619 & 0,8889 & 0,8400 & 0,6774 \\
\hline Concreto Pintado de Vermelho & 0,8182 & 0,3750 & 0,6154 & 0,2857 \\
\hline CRFS & 0,6875 & 0,2558 & 0,6364 & 0,1842 \\
\hline Fibra de Vidro & 0,7976 & 0,6147 & 0,3462 & 0,6279 \\
\hline Galvalume A & 0,6647 & 0,8779 & 0,6587 & 0,9244 \\
\hline Galvalume B & 0,8284 & 1,0000 & 0,9034 & 0,9161 \\
\hline Galvalume C & 0.8472 & 0.7093 & 0,6909 & 0.8261 \\
\hline Lago & 1,0000 & 0,7351 & 0,9904 & 0,9279 \\
\hline Lona & 0,7895 & 1,0000 & 0,2727 & 0,2500 \\
\hline Manta Asfáltica Aluminizada & 0,6905 & 0,6170 & 0,6364 & 0,6774 \\
\hline Pastilha Esmaltada & 0,6154 & 1,0000 & 0,4194 & 0,9286 \\
\hline Pedra Mineira & 0,5984 & 0,9012 & 0,6809 & 0,7805 \\
\hline Piscina de Azulejo & 0,9143 & 1,0000 & 0,9024 & 0,9250 \\
\hline Piscina de Vinil & 0,8571 & 0,2609 & 0,7500 & 0,7500 \\
\hline Plástico & 0,7000 & 0,5000 & 0,8276 & 0,8276 \\
\hline Policarbonato & 0,7857 & 0,3333 & 0,4231 & 0,1692 \\
\hline Solo Exposto & 0,6667 & 0,7667 & 0,4545 & 0,5556 \\
\hline Sombra & 0,7465 & 0,9671 & 0,7443 & 0,8327 \\
\hline Vegetação Arbórea & 0,8433 & 0,9638 & 0,7535 & 0,9081 \\
\hline Vegetação Rasteira & 0,9249 & 0,8655 & 0,8293 & 0,7727 \\
\hline Vidro Aramado & 0,5778 & 0,1503 & 0,7321 & 0,3306 \\
\hline
\end{tabular}

Provou-se também que o índice Kappa na classificação dos dados SpecTIR com o método Random Forest é significantemente superior ao Kappa para o método C4.5. Os testes de hipótese para o 
Nível de Legenda 1 também mostraram que, tanto para as classificações com o método C4.5 quanto para aquelas com o método Random Forest, as classificações obtidas com dados do sensor SpecTIR apresentaram resultados significantemente superiores às das classificações obtidas com dados do sensor WV-2. Para o Nível de Legenda 2, os testes de hipótese mostraram que os índices Kappa das classificações do método C4.5 foram significantemente superiores aos das classificações resultantes do Random Forest para os dois conjuntos de dados (WV-2 e SpecTIR).

Para o Nível de Legenda 2, constatou-se que as classificações obtidas com dados do sensor SpecTIR apresentaram resultados significativamente superiores aos das classificações obtidas com dados do sensor WV-2 para ambos os métodos.

Todas as classificações para as cenas WV-2 e SpecTIR obtiveram exatidão global superior a 70\%, ou seja, todas elas obtiveram qualidade considerada como muito boa ou excelente de acordo com Landis e Koch (1977).

O desempenho superior do sensor SpecTIR (357 bandas), de forma geral, era esperado, haja vista sua melhor resolução espectral quando comparada à do sensor WV-2 (8 bandas), isto é, uma vez que se aumenta o número de bandas, aumenta-se proporcionalmente o conteúdo informacional acerca do comportamento espectral dos alvos, e consequentemente, a capacidade de discriminação dos mesmos pelo respectivo sensor.

Em referência aos classificadores, o método C4.5 obteve desempenho superior em relação ao Random Forest em três das quatro análises comparativas. A performance comparativamente inferior do Random Forest foi devida ao reduzido número de árvores utilizado no experimento. De acordo com Hastie et al. (2009), quanto maior o número de árvores, maior a acurácia do método, que tende a estabilizar em torno de 200 árvores. Os experimentos utilizaram apenas 10 árvores, pois todas elas foram implementadas manualmente nó a nó no software eCognition 8.7. Tal implementação detalhada, descrita em Anjos (2016), foi realizada com o intuito de avaliar a capacidade de separabilidade dos atributos selecionados em cada uma das árvores em todos os experimentos, e desta forma, a implementação manual de 100 ou 200 árvores Random Forest se tornaria inviável.

Especificamente com relação aos dados SpecTIR, constatou-se que a acurácia do Nível de Legenda 2 foi superior à do Nível de Legenda 1 apenas para o método C4.5, sendo que para o método Random Forest a acurácia da classificação com dados SpecTIR foi superior no Nível 1. Isto pode ser explicado pelas restrições de implementação operacional deste método anteriormente descritas, somadas ao fato de que a redução no número de árvores comprometeu a acurácia dos resultados em vista do considerável aumento do número de classes no Nível 2. Quanto ao método C4.5, tal superioridade deve-se à especificidade das 38 classes do Nível 2, as quais originaram segmentos puros de classes de materiais que se encontram agrupadas em uma única classe no Nível 1, resultando em maior homogeneidade interna dos segmentos. Como exemplo, pode-se citar a classe Materiais Mistos e Coberturas Diversas do Nível 1, que é subdividida em 17 classes no Nível 2 (conforme Quadro 1), fato que proporciona a separabilidade de materiais extremamente diferentes, como, por exemplo: Acrílico, Cimento Amianto e Concreto Pintado de Vermelho, os quais integram uma mesma classe no Nível 1.

Tabela 4: Avaliação da qualidade da classificação dos dados SpecTIR com o método C4.5 e com o método Random Forest, para o Nível de Legenda 2. 


\begin{tabular}{|c|c|c|c|c|}
\hline & \multicolumn{2}{|c|}{ Método C4.5 } & \multicolumn{2}{|c|}{ Método Random Forest } \\
\hline Exatidão Global & \multicolumn{2}{|c|}{$90,83 \%$} & \multicolumn{2}{|c|}{$74,93 \%$} \\
\hline Kappa & \multicolumn{2}{|c|}{0,8988} & \multicolumn{2}{|c|}{0,7258} \\
\hline $\begin{array}{l}\text { Avaliação da Exatidão das } \\
\text { Classes }\end{array}$ & $\begin{array}{l}\text { Exatidão do } \\
\text { Produtor }\end{array}$ & $\begin{array}{l}\text { Exatidão do } \\
\text { Consumidor }\end{array}$ & $\begin{array}{l}\text { Exatidão do } \\
\text { Produtor }\end{array}$ & $\begin{array}{l}\text { Exatidão do } \\
\text { Consumidor }\end{array}$ \\
\hline Aço Galvanizado Brilhante & 0,9362 & 0,9072 & 0,7183 & 0,6892 \\
\hline Aco Galvanizado Ferrugem & 0,7500 & 1,0000 & 0,6154 & 0,3380 \\
\hline Aço Galvanizado Fosco & 0,9841 & 1,0000 & 0,7130 & 0,7938 \\
\hline Acrílico & 0,4286 & 0,7500 & 0,8750 & 0,0722 \\
\hline Amianto & 0,9065 & 0,9700 & 0,8247 & 0,7431 \\
\hline Asfalto & 0,9746 & 0,8496 & 0,7405 & 0,7698 \\
\hline Asfalto Pintado Branco & 0,9091 & 0,3636 & 0,5556 & 0,5882 \\
\hline Asfalto Pintado Vermelho & 0,8696 & 0,5263 & 0,7143 & 0,3846 \\
\hline Bloquete & 0,8784 & 0,8333 & 0,5375 & 0,7679 \\
\hline Carvão Coque & 0,9091 & 0,8537 & 0,8529 & 0,8657 \\
\hline Cerâmica Escura & 0,6316 & 0,2791 & 0,5652 & 0,5417 \\
\hline Cerâmica Iluminada & 0,3750 & 0,5455 & 0,8824 & 0,6522 \\
\hline Cimento & 0,8750 & 0,8235 & 0,7857 & 0,3438 \\
\hline Cimento Pintado de Verde & 0,9724 & 0,8198 & 0,7554 & 0,9052 \\
\hline Cimento Pintado de Vermelho & 0,9787 & 0,7667 & 0,9813 & 0,7095 \\
\hline Concreto & 0,8381 & 0,9367 & 0,8778 & 0,7874 \\
\hline Concreto Impermeabilizado & 1,0000 & 0,8571 & 0,8081 & 0,8163 \\
\hline Concreto Pintado de Amarelo & 0,7000 & 0,9130 & 0,7308 & 0,9500 \\
\hline Concreto Pintado de Vermelho & 1,0000 & 1,0000 & 1,0000 & 0,8571 \\
\hline CRFS & 0,8889 & 1,0000 & 0,3148 & 0,9444 \\
\hline Fibra de Vidro & 1,0000 & 0,9231 & 0,8462 & 0,8021 \\
\hline Galvalume A & 0,8469 & 0,9833 & 0,5489 & 0,9099 \\
\hline Galvalume B & 1,0000 & 0,8606 & 0,9726 & 0,7320 \\
\hline Galvalume C & 0,8551 & 1,0000 & 0,7368 & 0,8400 \\
\hline Lago & 1,0000 & 0,8848 & 0,9571 & 0,9710 \\
\hline Lona & 0,6667 & 1,0000 & 0,8333 & 0,8333 \\
\hline Manta Asfáltica Aluminizada & 0,7778 & 0,8537 & 0,7273 & 0,9412 \\
\hline Pastilha Esmaltada & 0,7500 & 0,4615 & 0,8125 & 0,8667 \\
\hline Pedra Mineira & 0,7634 & 1,0000 & 0,6883 & 0,6709 \\
\hline Piscina de Azulejo & 0,9535 & 1,0000 & 0,9000 & 1,0000 \\
\hline Piscina de Vinil & 1,0000 & 1,0000 & 0,7368 & 0,3415 \\
\hline Plástico & 0,8101 & 0,9412 & 0,8642 & 0,8333 \\
\hline Policarbonato & 0,3000 & 0,0472 & 0,9643 & 0,6585 \\
\hline Solo Exposto & 0,6905 & 0,8286 & 0,6885 & 0,4565 \\
\hline Sombra & 0,8352 & 0,9939 & 0,5000 & 0,9776 \\
\hline Vegetacão Arbórea & 0,9697 & 0,9761 & 0,9043 & 0,6167 \\
\hline Vegetação Rasteira & 0,9671 & 0,9808 & 0,7598 & 0,8935 \\
\hline Vidro Aramado & 0,7500 & 0,9231 & 0,9200 & 0,6765 \\
\hline
\end{tabular}

Todas as classificações em ambos os níveis de legenda apresentaram exatidão global superior a $70 \%$; entretanto, quando se realiza uma análise detalhada dos resultados, percebe-se que algumas das classes apresentaram resultados inferiores a outras classes. Para as classificações do Nível de Legenda 1, a classe de pior desempenho, de acordo com as Tabelas 1 e 2, é a classe Materiais Mistos e Coberturas Diversas. Isto é justificado pela grande diversidade de materiais presentes no ambiente urbano que compõem esta classe. Para as classificações do Nível de Legenda 2, as classes de pior desempenho, de acordo com as Tabelas 3 e 4, são aquelas que apresentam as menores áreas no terreno e comportamento espectral não particularizado (i.e., com confusão em relação a outras classes), como Acrílico, Cerâmica Iluminada, Cerâmica Escura e Policarbonato. Neste caso, a seleção de amostras para treinamento das mesmas fica limitada face ao reduzido número de segmentos passíveis de serem coletados, e da mesma forma, a seleção de pontos amostrais aleatórios para sua validação torna-se comprometida.

Por fim, constata-se que as classificações do Nível de Legenda 1 não apresentam novidades ao estado da arte, haja vista a existência de trabalhos semelhantes na literatura, como os de Pinho et al. (2012), com 11 classes de cobertura do solo urbano e índice de concordância Kappa de 0,87; Ghamisi et al. (2015), com nove classes e Kappa de 0,98; Eslami e Mohammadzadeh (2016), com sete classes e Kappa de 0,90, entre outros. Já as classificações do Nível de Legenda 2 chegam a um grau de detalhamento ainda não reportado na literatura de sensoriamento remoto, sendo que dentre os trabalhos já publicados com elevado número de classes de cobertura do solo urbano, o número máximo de classes reportado até o momento diz respeito ao trabalho de Franke et al. 
(2009), com 20 classes e exatidão global de 97,2\%, realizado por classificação pixel a pixel. Outros trabalhos recentes, porém com número inferior de classes, referem-se a Taherzadeh e Shafri (2011), com 14 classes e Kappa de 0,88; Longbotham et al. (2012), com 15 classes e Kappa variando de 0,74 a 0,94; Khodadadzadeh et al. (2014; 2015), com 16 e 15 classes, respectivamente, com exatidões globais oscilando de 72,9\% a 92,5\% em ambos os trabalhos.

Como recomendações para trabalhos futuros, citam-se: i) a avaliação de novos métodos de classificação, como, por exemplo, o classificador Máquina de Vetor de Suporte (Support Vector Machine - SVM); ii) a aplicação de rotinas de pré-seleção de atributos, a fim de se testar a similaridade entre classificações com o conjunto de dados completo e classificações com o conjunto reduzido; iii) a simulação dos dados WV-2 por meio dos dados SpecTIR, para testar o desempenho das imagens em uma mesma geometria de aquisição e iluminação; e iv) a criação de um terceiro conjunto de dados, formado conjuntamente por imagens WV-2 e SpecTIR, a fim de avaliar se um conjunto de dados híbrido é capaz de obter melhores resultados do que o conjunto hiperespectral isoladamente.

\section{Conclusões}

Todas as classificações apresentaram exatidão global e índice Kappa superiores a 0,70. O teste de similaridade $\mathrm{Z}$ comprovou que nenhuma das classificações pode ser considerada similar em termos de acurácia dos resultados. Para o Nível de Legenda 1, contendo 11 classes de cobertura do solo urbano, é possível destacar que todo o conjunto de dados SpecTIR foi significantemente superior ao conjunto WorldView-2. Assim, para esse nível de detalhamento, pode-se afirmar que a classificação dos dados provenientes do sensor SpecTIR com o método Random Forest provou ser a que mais se aproximou do dado de referência.

Já para o Nível de Legenda 2, com 38 classes de cobertura do solo urbano, cabe realçar que o método C4.5 apresentou resultados significantemente melhores do que o método Random Forest, e que o os resultados obtidos com o conjunto de dados SpecTIR foi significantemente superior aos resultados obtidos pelo conjunto de dados WV-2. Isto permite evidenciar a classificação dos dados SpecTIR com o método C4.5 como sendo aquela que mais se aproximou do dado de referência, atingindo uma exatidão global superior a $90 \%$, o que demonstra ser um resultado surpreendente em vista do elevado nível de detalhamento da legenda de classes.

Cabe salientar, enfim, que a discriminação detalhada de materiais de cobertura do solo urbano, os quais compreendem materiais de pavimentação viária e não-viária, vegetação, corpos d'água, solo exposto e materiais de recobrimento de edificações (lajes, telhados, coberturas em geral, parapeitos, brises etc.), pode ser útil para fins de: (i) estimativas de reflectância desses materiais de superfície e da consequente determinação de sua contribuição para com o fenômeno de ilhas de calor urbanas, além de sua interferência no microclima urbano (ii) diferenciação entre coberturas vãs e permanentes, bem como detecção de piscinas irregularmente construídas para fins de tributação imobiliária urbana, (iii) identificação de materiais com compostos agressivos à saúde e/ou suposta ou reconhecidamente cancerígenos e da avaliação da sua relação com a incidência de patologias, entre outras finalidades investigativas e fiscalizatórias.

Pode-se, portanto, argumentar em prol de um número cada vez mais elevado de classes de cobertura, como as 38 classes de cobertura do solo urbano empregadas neste trabalho, a despeito do posicionamento em contrário observado atualmente em meio à comunidade científica. É mister refletir que, se o sensoriamento remoto evoluiu com o passar dos anos, possibilitando a utilização 
de imagens de resolução espacial submétrica e hiperespectrais, os métodos e as análises para a exploração de tais dados devem da mesma forma concomitantemente evoluir. Espera-se que o progressivo avanço dos sensores remotos nos motive a buscar resultados mais refinados a cada nova análise. Neste sentido, o presente trabalho avançou no estado da arte por trabalhar em um nível de detalhamento particularizado do ambiente urbano, não reportado até o momento na literatura indexada. Novos métodos de classificação e mineração de dados poderão ser testados, assim como novos métodos da avaliação da qualidade, visto que dados hiperespectrais se enquadram em um amplo e novo campo do conhecimento denominado "big data" (Lohr, 2012; Cervone et al., 2013), o qual certamente irá nos impor crescentes desafios, ao mesmo tempo em que descortinará uma multiplicidade de novas oportunidades de investigação científica.

\section{REFERÊNCIAS BIBLIOGRÁFICAS}

Andrade, Leidiane L. "Estimativa da Temperatura e Emissividade com Imagens do Sensor HSS (Hyperspectral Scanner System) e suas Relações com Materiais Urbanos". Master diss., Instituto Nacional de Pesquisas Espaciais, 2011.

Anjos, Camila S. "Classificação de áreas urbanas com imagens multiespectrais e hiperespectrais utilizando métodos não paramétricos”. PhD diss., Instituto Nacional de Pesquisas Espaciais, 2016.

Breiman, Leo. "Random Forests". Machine Learning 1 (2001): 5-32. Accessed December 27, 2015. doi: 10.1023/A:1010933404324.

Cervone, Guido, Lin, J.; and Waters, N. Data Mining for Geoinformatics: Methods and Applications. New York : Springer, 2013.

Congalton, Russell G, and Green, K. Assessing the accuracy of remotely sensed data: principles and practices. New York: Lewis Publishers, 2009.

Definiens. Definiens Developer 7 - Reference Book - Version 7.0.0.843. Last modified March 11, 2012. http://www.definiens.com.

Digital Globe. The Benefits of the 8 Spectral Bands of WorldView-2 Last modified March, 2010. http://global.digitalglobe.com/sites/default/files/DG-8SPECTRAL-WP_0.pdf.

Eslami, Mehrdad, and Mohammadzadeh, A. "Developing a spectral-based strategy for urban object detection from airborne hyperspectral TIR and visible data." IEEE Journal of Selected Topics in Applied Earth Observations and Remote Sensing 9 (2016):1808-1816. Accessed January 20, 2016. doi: 10.1109/JSTARS.2015.2489838.

Francisco, Cristiane. N., and Almeida, C. M. "Avaliação de Desempenho de Atributos Estatísticos e Texturais em uma Classificação de Cobertura da Terra Baseada em Objeto." Boletim de Ciências Geodésicas 18 (2012): 302-326. Accessed December 27, 2015. Accessed January 20, 2016. doi: 10.1590/S1982-21702012000200008.

Franke, Jonas, Roberts, D. A. Halligan, K., and Menz, G. "Hierarchical Multiple Endmember Spectral Mixture Analysis (MESMA) of hyperspectral imagery for urban environments." Remote Sensing of Environment 113 (2009): 1712-1723. Accessed January 20, 2016. doi:10.1016 /j.rse.2009.03.018. 
Ghamisi, Pedram, Wu, D., Cavallaro, G., Benediktsson, J. A.; Phinn, S.; and Falco, N. "An advanced classifier for the joint use of LiDAR and hyperspectral data: Case study in Queensland, Australia." Paper presented at the IEEE International Geoscience and Remote Sensing Symposium (IGARSS), Milan, Italy, July 26-31, 2015. Accessed January 20, 2016. doi:10.1109/IGARSS.2015.7326281.

Gislason, Pall O., Benediktsson, J. A., and Sveinsson, J. R. "Random Forests For Land Cover Classification". Pattern Recognition Letters 4 (2006): 294-300. Accessed December 27, 2015. doi: 10.1016/j.patrec.2005.08.011.

Han, Jiawei, Kamber, M., and Pei, J. Data Mining: Concepts And Techniques. Whaltan: Elsevier, 2012.

Hastie, Trevor, Tibshirani, R. J., and Friedman, J. H. The elements of statistical learning: data mining, inference, and prediction. New York: Springer, 2009.

Herold, Martin, Gardner, E. M., and Roberts, D.A. "Spectral Resolution Requirements For Mapping Urban Areas." IEEE Transactions on Geoscience and Remote Sensing 41 (2003): 19071919. Accessed December 27, 2015. doi: 10.1109/TGRS.2003.815238.

Jensen, John R. Sensoriamento Remoto Do Ambiente: Uma Perspectiva Em Recursos Terrestres. Translated by José Carlos Neves Ephiphanio. São José Dos Campos: Parêntese, 2009.

Khodadadzadeh, Mahdi, Jun L., Plaza, A., and Bioucas-Dias, J. M."Hyperspectral image classification based on union of subspaces." Paper presented at the Urban Remote Sensing Event (JURSE), Lausanne, Suíça, March 30 - April 1, 2015. doi: 10.1109/JURSE.2015.7120510.

Khodadadzadeh, Mahdi, Jun, L., Plaza, A., Gamba, P., Benediktsson, J. A., and Bioucas-Dias, J. M. "A new framework for hyperspectral image classification using multiple spectral and spatial features". Paper presented at the IEEE INTERNATIONAL GEOSCIENCE AND REMOTE SENSING SYMPOSIUM (IGARSS), 2014, Quebec, Canada. July 13-18, 2014. doi: 10.1109/IGARSS.2014.6947524.

Körting, Thales S., Fonseca, L. M. G., and Câmara, G. "GeoDMA - Geographic Data Mining Analyst." Computers \& Geosciences 57 (2013): 133-145. Accessed December 27, 2015. doi: 10.1016/j.cageo.2013.02.007.

Laben, Craig A., and Brower, B. V., 2000. Process for enhancing the spatial resolution of multispectral imagery using pan-sharpening. United States Patent No. 6011875.

Laboratório de Visão Computacional - LVC, 2006. InterIMAGE 1.30 - Manual do Usuário. Accessed January 15, 2016, http://www.lvc.ele.puc-rio.br/projects/interimage/pt-br/ documentacao /arquivos/InterImage\%201.30\%20-\%20Manual\%20do\%20Usu\%C3\%A1rio.pdf.

Landis, J. R., and Koch, G. G. "The measurement of observer agreement for categorical Data." Biometrics 33 (1977): 159-174. Accessed January 20, 2015. doi: 10.2307/2529310.

Leonardi, Fernando. “Abordagens Cognitivas e Mineração de Dados Aplicadas a Dados Ópticos Orbitais e de Laser para a Classificação de Cobertura do Solo Urbano". Master diss., Instituto Nacional de Pesquisas Espaciais, 2010.

Leonardi, Fernando, Almeida, C. M., Fonseca, L. M. G., and Tomas, L. R. “An ALTM digital height model associated with VHR imagery for an object-based classification of intra-urban targets". Paper presented at the Joint Urban Remote Sensing Event, São Paulo, Brazil, April, 2123, 2013. doi: 10.1109/JURSE\#.2013.6550723.

Lohr, Steve. "The Age of Big Data". The New York Times. Last modified February, 11, 2012. http://www.nytimes.com/2012/02/12/sunday-review/big-datas-impact-in-the-world.html. 
Longbotham, Nathan, Chaapel, C., Bleiler, L., Padwick, C., Emery, W. J., and Pacifici, F. "Very high resolution multiangle urban classification analysis." IEEE Transactions on Geoscience and Remote Sensing 50 (2012): 1155-1170, 2012. Accessed January 12, 2016.doi: 10.1109/TGRS.2011.2165548.

Manolakis, Dimitris, Marden, D., and Shaw, G. "Hyperspectral image processing for automatic target detection applications". Lincoln Laboratory Journal 14 (2003): 79-116.

Pinho, Carolina M. D., Fonseca, L. M. G., Korting T. S., Almeida, C. M., and Kux, Hermann J. H. "Land-cover classification of an intra-urban environment using highresolution images and objectbased image analysis". International Journal of Remote Sensing 33 (2012): 5973-5995. Accessed January 20, 2016. doi: abs/10.1080/01431161.2012.675451.

Quinlan, John Ross. C4. 5: Programs For Machine Learning. Elsevier, 2014.

Taherzadeh, Ebrahim, and Shafri, H.Z.M. Using hyperspectral remote sensing data in urban mapping over Kuala Lumpur. Paper presented at the URBAN REMOTE SENSING EVENT (JURSE), 2011, Munich, Germany, April 11-13, 2011. doi: 10.1109/JURSE.2011.5764805.

Taherzadeh, Ebrahim, Shafri, H. Z. M., Mansor, S., and Ashurov, R. "A comparison of hyperspectral data and WorldView-2 images to detect impervious sSurface". Paper presented at the Hyperspectral Image and Signal Processing: Evolution in Remote Sensing, Shangai, China, June 4-7, 2012.

Tso, Brandt, and Mather, P. Classification Methods For Remotely Sensed Data. Boca Raton: Taylor \& Francis, 2009.

Walton, Jeffrey T. "Subpixel urban land cover estimation: Comparing cubist, random forests, and support vector regression". Photogrammetric Engineering \& Remote Sensing 74 (2008): 12131222. Weber, Robert A., and O’Connell, K. M. “Alternative Futures: United States Commercial Satellite

Imagery In 2020". Last modified November, 2011.

http://nsarchive.gwu.edu/NSAEBB/NSAEBB404/docs/37.pdf .

Wright, Conrad, Riley, D. N., Peppin, W. A., and Schulenburg, N. W. "Mineral exploration in the Western United States using visible - short wave infrared and a mid wave - long wave infrared hyperspectral imagers: Joint airborne collection using hyperspectral systems - Spectir Corporation, 2011". Last modified 2012. http://www.spectir.com/wpcontent/uploads/2012/02/ProSpecTIR_SEBASS_Mineral_Exploratio n_Collect.pdf.

Recebido em 31 de dezembro de 2015.

Aceito em 23 de novembro de 2016.

\section{ERRATA}

Página 371, Onde se lia:

Camila Souza dos Anjos Lacerda ${ }^{1,2}$

Cláudia Maria de Almeida ${ }^{1}$ 
Lênio Soares Galvão ${ }^{1}$

Carlos Roberto Souza Filho ${ }^{3}$

${ }^{1}$ Divisão de Sensoriamento Remoto, Instituto Nacional de Pesquisas Espaciais - INPE. São José dos Campos, Brasil. Email: camilasa@ieav.cta.br; almeida@dsr.inpe.br, lenio@dsr.inpe.br

2Subdivisão de Sensoriamento Remoto, Instituto de Estudos Avançados - IEAv, Força Aérea Brasileira FAB. São José dos Campos, Brasil.

IInstituto de Geociências, Universidade de Campinas - UNICAMP. Campinas, Brasil. Email: beto@ige.unicamp.br

Leia-se:

Camila Souza dos Anjos ${ }^{1,2}$

Cláudia Maria de Almeida ${ }^{1}$

Lênio Soares Galvão ${ }^{1}$

Carlos Roberto Souza Filho ${ }^{3}$

Marielcio Gonçalves Lacerda ${ }^{2}$

Ronaldo Cristiano Prati 4

${ }^{1}$ Divisão de Sensoriamento Remoto, Instituto Nacional de Pesquisas Espaciais - INPE. São José dos Campos, Brasil. Email: camilasa@ieav.cta.br; almeida@dsr.inpe.br, lenio@dsr.inpe.br

${ }^{2}$ Subdivisão de Sensoriamento Remoto, Instituto de Estudos Avançados - IEAv, Força Aérea Brasileira FAB. São José dos Campos, Brasil. Email: marielcio@ieav.cta.br

3 Instituto de Geociências, Universidade de Campinas - UNICAMP. Campinas, Brasil. Email: beto@ige.unicamp.br

${ }^{4}$ Centro de Matemática Computação e Cognição, Universidade Federal do ABC. Santo André, Brasil. Email: rcprati@gmail.com

Boletim de Ciências Geodésicas (2017) 23(3):389. 